\title{
Evaluation of Outcome of Fracture Neck of Femur Treated with Dynamic Hip Screw and Antirotation Screw for Early Mobilisation in Young Adults
}

Dr. Sharma Nishant ${ }^{*}$, Dr. Goel Rajesh, Dr. Gupta Shobit, Dr. Patidar Balkishan

DOI: $10.36347 /$ sjams.2020.v08i06.025

| Received: 07.06.2020 | Accepted: 15.06.2020 | Published: 24.06.2020

*Corresponding author: Dr. Nishant Sharma

Abstract

Objectives: The treatment of femoral neck fractures shows a relatively high number of poor outcomes, usually due to late complications, such as avascular necrosis of the femoral head,non/mal union. The aim of this prospective study was to evaluate a group of patients treated by osteo-synthesis for intra-capsular femoral neck fractures at our department, and to find appropriate implant choice for subtype of fracture neck of femur and complication. Methods: A prospective study carried out on 30 patients aged 18-55 years, who had complete femoral neck fracture. All fractures were classified on the basis of pauwel'sand anatomical classification.All patients were treated between 2 to 7 days after injury and followed for 12 months. Results: Basicervical type fractures were diagnosed in 10 patients, transcervical 12 and 8 had subcapital type fractures. Bone union without complications was achieved in $66.6 \%$ of the patients within 12 months of surgery. Late complications were found in $33.3 \%$ fracture. Conclusion: DHS with derotation screw is biomechanically and functionally very stable construct for fixation of fracture neck of femur fracture in young adults.in basicervical and transcervical types of fracture, results are satisfactory but in subcapital types of fracture its use is still in dilemma.

Keywords: Femoral neck fracture, dhs with derotaion screw, avascular necrosis.

Copyright @ 2020: This is an open-access article distributed under the terms of the Creative Commons Attribution license which permits unrestricted use, distribution, and reproduction in any medium for non-commercial use (NonCommercial, or CC-BY-NC) provided the original author and source are credited.

\section{INTRODUCTION}

Femoral neck fractures include injuries involving the area between the head of the femur and the intertrochanteric line. They are divided into intracapsular and extracapsular, according to their relation to the hip capsule [1]. Hip fractures account for around $20 \%$ of the surgical fractures seen at orthopedic trauma units and generate significant annual cost in any healthcare system. Femoral neck fractures account for approximately $50 \%$ of all fractures of the hip region. (2).These fractures represent an increasing burden on healthcare globally, with the number of hip fractures occurring worldwide expected to increase from 1.66 million in 1990 to 6.26 million fractures in 2050 [3].

Among young adults, fractures in the hip region are generally uncommon. However, because of high-energy accidents involving sports practices and traffic accidents, this incidence has been increasing. The pattern of this type of fracture frequently has a vertical line with unstable characteristics, classified as Pauwels III. This classification correlates the prognosis with the angle of the fracture plane: as the angle increases, the instability of the fracture also increases and the complications relating to its fixation and consolidation worsen [4].

Management of the fracture neck femur is still a dilemma for orthopaedic surgeon, and remains in many ways the unsolved fracture as far as treatment and results are concerned. Every time a new method in management of these fractures generates lots of hope but long term follow up results makes things fall apart and brings us down to same ground again.

The treatment for femoral neck fractures varies according to the patient's age and the fracture pattern [5]. In young patients, osteosynthesis should always be prioritized, while in older patients, arthroplasty should be cogitated. For middle-aged patients (40-65 years), the indication should be defined individually [6].

Early accurate anatomical reduction, compression of the fracture, and rigid internal fixation are used to promote union, but we probably have less control over avascular necrosis of femoral head, 
because it depends on various internal and external factors. Even after good anatomical reduction and fixation in time limit, sometime patient leads to avascular necrosis

\section{MATERIAL \& MeTHOdS}

This was a prospective study conducted in department of orthopaedics, Governmentt medical college, Kota in 2014 with follow up period of 12 months.

30 patients of $18-55$ years age group who did not have any other comorbidity and associated fractures were included. Patients presented to the emergency department with fracture neck of femur diagnosed y plain radiograph and classified according to pauwels and anatomical classification.

\section{Operative technique}

A closed reduction was obtained under spinal or general anaesthesia and conformed using an image intensifier. A straight lateral incision was made from the greater trochanter and extended distally along the thigh. Using an angle guide, a threaded guide pin was inserted at the subcapital level of the femoral head. A second guide pin was placed parallel and superior to the main guide pin at a distance of about $13 \mathrm{~mm}$. This provided temporary rotational stability for the fracture and prevented spinning of the head-neck fragment during reaming or screw insertion. After screw insertion, the plate was fixed to the shaft. Then, a cannulated cancellous screw, of suitable length, with washer was inserted onto the second guide pin to act as a DRS. A suction drainage system was inserted and the wound was closed.

\section{RESULTS}

A total of 30 patients were included in study and their age line data listed in table 1.youngest age of the patient was 20 year and oldest being was 55 year.

Table-6: Results in pauwel's type fractures

\begin{tabular}{|c|c|c|c|c|c|}
\hline \multirow{2}{*}{$\begin{array}{c}\text { PAUWEL'S } \\
\text { CLASSFICATION }\end{array}$} & \multicolumn{3}{|c|}{ ON BASIS OF SALWATI WILSON } & \multirow{2}{*}{$\begin{array}{c}\text { TOTAL } \\
\text { SCORE }\end{array}$} \\
\cline { 2 - 5 } & $\begin{array}{c}\text { EXCEL } \\
\text { LENT }\end{array}$ & GOOD & FAIR & POOR & \\
\hline TYPE I & 4 & 4 & 0 & 0 & 8 \\
\hline TYPE II & 3 & 8 & 1 & 0 & 12 \\
\hline TYPE III & 4 & 2 & 2 & 2 & 10 \\
\hline TOTAL & 11 & 14 & 3 & 2 & 30 \\
\hline
\end{tabular}

1. Table-7: Results in different anatomical fractures configurations

\begin{tabular}{|c|c|c|c|c|c|}
\hline \multirow{2}{*}{$\begin{array}{c}\text { ANATOMICAL } \\
\text { CLASSIFICATION }\end{array}$} & \multicolumn{4}{|l|}{ ON BASIS OF SALWATI WILSON SCORE } & \multirow{2}{*}{ TOTAL(30) } \\
\cline { 2 - 5 } & EXCELLENT & GOOD & FAIR & POOR & \\
\hline BASICERVICAL & 7 & 3 & 0 & 0 & 10 \\
\hline TRANSCERVICAL & 3 & 7 & 2 & 0 & 12 \\
\hline SUBCAPITAL & 1 & 4 & 1 & 2 & 8 \\
\hline TOTAL & 11 & 14 & 3 & 2 & 30 \\
\hline
\end{tabular}

In our study, none of the patient had poor result with pauwel'S type I and II fracture. 2 patients had poor results and both of them had pauwels's type III fracture. Pauwel's type 3 femoral neck fractures are problematic to treat, with non-union rates higher than those reported for historical controls. In one of the studies on Pauwel's type III fractures [7] non-union rate of $16 \%$ was reported with cannulated screws and $8 \%$ with fixed angle device and supports the theory that these type 3 fractures experience shear and may demonstrate a higher rate of varus, shortening, and nonunion. In our study, 8 patients had pauwel's type III fracture,among them 4 patients had excellent result, 2 had good, 2 fair and 2 had poor results. 2 patients had varus collapse and 2 patients had screw cut out and 1 had non-union
In our study we found that results are favourable in basicervical and transcervical type fracture. We have found limitation of this construct in high subcapital fracture where DHS threads won't have enough purchase in femoral head(8).In our study ,8 patients had subcapital type fracture.among them 1 had excellent and 4good, 1 fair and 2 had poor result.none of the basicervical and transcervical type fracture group patients had poor result..2 of the patients had screw cut out, 1 patient had nonuion, 1 patient had varus collapse and 2 had stiffness

\section{DISCUSSION}

Worldwide it has been shown that THR is superior to internal fixation considering the rehabilitation and complications $[9,10,11,12]$ but it does not hold Managment of fracture neck of femur is 
still an unsolved mystery specially in young adults. Within a dilemma while making decision to prevent the native bone or to replace it. True for young active patient and inclined to preserve the head by internal fixation.

Fracture configuration plays an important role in overall results and complication. Mostcommon type of fracture configuration in our series was pauwel's type II $40 \%$ (12 out of 30) and according to anatomical classification, transcervical type is the commonest one.This is similar to the series of Mayankgupta et al. [13] Of the 30 patients.

\section{Conclusion}

Femoral neck fractures in young adults are relatively uncommon. They usually occur as a result of high energy trauma and patients often have associated injuries.DHS with derotation screw is biomechanically and functionally very stable construct for fixation of fracture neck of femur in young adults.Inbasicervical and transcervicaltypes of fracture, results are satisfactory but in subcapital type fractures its use is still in dilemma.

\section{REFRENCES}

1. Damany DS, Parker MJ, Chojnowski A. Complications after intracapsular hip fractures in young adults: a meta-analysis of 18 published studies involving 564 fractures. Injury. 2005 Jan 1;36(1):131-41.

2. Heckman JD, McKee M, McQueen MM, Ricci W, Tornetta III P. Rockwood and Green's fractures in adults. Lippincott Williams \& Wilkins; 2014 Sep 4.

3. E. Dennison, M.A. Mohamed, C. Cooper "Epidemiology of osteoporosis" Rheum Dis Clin North Am, 32 (2006), pp. 617-629

4. Heckman JD, McKee M, McQueen MM, Ricci W, Tornetta III P. Rockwood and Green's fractures in adults. Lippincott Williams \& Wilkins; 2014 Sep 4.

5. Yih-Shiunn L, Chien-Rae H, Wen-Yun L. Surgical treatment of undisplaced femoral neck fractures in the elderly. International orthopaedics. 2007 Oct 1;31(5):677-82.

6. Singer BR, McLauchlan GJ, Robinson CM, Christie J. Epidemiology of fractures in 15000 adults: the influence of age and gender. The Journal of bone and joint surgery. British volume. 1998 Mar;80(2):243-8.

7. Liporace F, Gaines R, Collinge C, Haidukewych GJ. Results of internal fixation of Pauwels type-3 vertical femoral neck fractures. JBJS. 2008 Aug 1;90(8):1654-9.

9. Singh MP, Aggarwal AN, Arora A, Dhammi IK, Singh J. Unstable recent intracapsular femoral neck fractures in young adults: osteosynthesis and primary valgus osteotomy using broad dynamic compression plate. Indian journal of orthopaedics. 2008 Jan;42(1):43.

10. Bhandari M, Devereaux PJ, Swiontkowski MF, Tornetta III P, Obremskey W, Koval KJ, Nork S, Sprague S, Schemitsch EH, Guyatt GH. Internal fixation compared with arthroplasty for displaced fractures of the femoral neck: a meta-analysis. JBJS. 2003 Sep 1;85(9):1673-81.

11. Parker MJ, Blundell C. Choice of implant for internal fixation of femoral neck fractures: metaanalysis of 25 randomised trials including 4,925 patients. Acta Orthopaedica Scandinavica. 1998 Jan 1;69(2):138-43.

12. Gjertsen JE, Vinje T, Engesaeter LB, Lie SA, Havelin LI, Furnes O, Fevang JM. Internal screw fixation compared with bipolar hemiarthroplasty for treatment of displaced femoral neck fractures in elderly patients. JBJS. 2010 Mar 1;92(3):61928.

13. Lowe JA, Crist BD, Bhandari M, Ferguson TA. Optimal treatment of femoral neck fractures according to patient's physiologic age: an evidence-based review. Orthopedic Clinics. 2010 Apr 1;41(2):157-66.

14. Gupta M, Arya RK, Kumar S, Jain VK, Sinha S, Naik AK. Comparative study of multiple cancellous screws versus sliding hip screws in femoral neck fractures of young adults. Chinese Journal of Traumatology. 2016 Aug 1;19(4):20912. 